Should these cases be classed together? Would it not be well to have institutions for cerebral disease, not insanity, as well as for insanity itself?

I may treat this subject more at length hereafter. At present, I content myself with drawing your attention to the important subject. I am, Sir, your obedient servant, Marshalr. Hall.

14, Manchester-square, Feb. 24, 1840.

\section{TREATMENT OF RHEUMATISM AND PERICARDITIS.}

\section{To the Editor of The LANCET.}

Srr :-Having seen, in a late Number of The Lancer, a case and observations on rheumatic fever, by Dr. Smith, I beg leave, through the same valuable medium, to offer a few remarks upon it. The case adduced does not appear to be one of mere rheumatism, and the observations appended seem laudatory of the treatment adopted. How far it was suecessful may be judged of by the result. $P$-'s attack commenced Oct. 16, and on Nov. 15 (last visit), after the lapse of a month, the report runs"Slight restraint in dilatation of chest; respiratory murmur audible, but weaker than natural ; pulse starting, between 95 and 100 ; sounds of heart louder, more abrupt, more diffused than natural, and first sound accompanied by a sonorous bruit de soufflet." Is this case brought forward as a cure? or is it calculated to put the line of treatment pursued in a favourable light? Can we wonder at reading, somewhat farther on, that, in six months after, a return of the disease carried off the patient?

If the case at all proves anything, it is this-that bleeding and mercury do not constitute the best treatment, either to relieve the pain, shorten the duration, or prevent the recurrence of rheumatism, more especially when pericarditis has ensued.

Dr. Corrigan, of Dublin, in a paper published in the "6 Dublin Journal," Nov., 1839, has given us the result of eight cases, treated and cured by opium. Having seen the treatment of his hospital cases, I can vouch for their accuracy, and I had then the opportunity of contrasting it with the antiphlogistic plan adopted in another part of the hospital, with nearly the same as Dr. Smith's success.

As I should injure the author's paper by curtailing it, I shall only give a few of the results which he has drawn together at its close.

The treatment of rheumatism by full doses of opium (averaging abont 10 or 12 grains

* "Observations on the Treatment of Acute Rhenmatism by Opium." By D.J. Corrigan, M.D. in 24 hours) has the following advantages :-

1. It shortens the duration of the attack. The duration under antiphlogistic treatment averages 26 days; ditto opiate, 9 days.

2. It relieves pain; opiate treatment does not constipate the bowels, or narcotise; and even when the night is passed without a sleep, " it is passed in calm quietness."

3. It does not reduce the patient's strength, or render him liable to the supervention of other disease.

4. It more certainly prevents the compli. cation of endo-carditis or pericarditis. In almost every case treated antiphlogistically the fibrous tissues of the heart were attacked, while in Dr. C.'s opiate treatment not one instance occurred.

The reasons for adopting this plan $I$ shall not trespass longer on your tine to enumerate, but refer the reader to Dr. C.'s paper, where he will be convinced of their accordance with true pathological principles, and also find a satisfactory explanation of the occurrence of pericardial effusions in acute rheumatism. I remain, Sir, yours,

Thos. Antrsell, M.R.C.S.L.

Vauxhall, Feb. 10, 1840.

\section{MEDICAL RELIEF IN THE UNIONS.}

\section{To the Editor of THE LANCET.}

Srr:-I am one of those who have waited with considerable solicitude the appearance of the plan by which the Poor-Law Commissioners propose to carry out the recommendation of the Parliamentary Committee and the pledges of their last Minute, and I confess I am disappointed that another year is to be commenced under the degrading system of Tender. I was anxious to learn if such would be the case, and, therefore, addressed a letter to the Poor-Law Commissioners on the subject. The reply I subjoin, which you may, perhaps, think proper to insert in your next Number, for the information of your numerous readers.

I, together with several medical peigh. bours, have adopted the Petition for Medical Reform which was recommended by the British Medical Association; and I trust that every country practitioner will imme. diately co-operate in endea vouring to effect what will be so conducive to the best inte rests of the profession and to the public generally. I am, Sir, yours,

L. OWen Fox.

Broughton, Stockbridge, Hants, March 2, 1840.

[As the letter of Mr. Chadwick is an official and not a private communication, we give it a place in print.] 
" Poor-Law Commission Office, " Feb. 8, 1840.

"Sir :-The Poor-Law Commissioners acknowledge the receipt of your letter of the 12th instant, and, in answer to your inquiry contained therein, desire to state that they have reported fully to Her Majesty's Government on the subject of Medical Relief (amongst other things), which Report will be laid before Parliament in the course of the present session, and that the Commis. sioners will not recommend any general and uniform system of Medical Relief to the Boards of Guardians until that Report shall have been presented to Parliament,

"Signed, by Order of the Board, " E. Chadwick, Secretary.

"To L O. Fox, Esq., Surgeon,

"Broughton, Stockbridge."

\section{ELECTION OF MEDICAL OHFICERS IN THE UNIONS.}

\section{To the Editor of The Lancet.}

SIR:-It is much to be regretted that the Poor-Law Commissioners do not, by some decisive step, put an end to the heartburnings which annually occur upon the election of Medical Officers in the Unions. On these occasions the manouvrings and trickery practised in some parts of the country, are not only disgraceful to the law itself, but highly injurious to the interest of both poor and parish.

I know a case which strikingly illustrates the little care bestowed by the Guardians in their selection of Medical Officers to Unions; it occurred in the Stratton Union, Cornwall. The two senior pratitioners there, one claiming to be the "oracle" of the place, and the other a sort of "light from the west," are neither of them members of the Hall or College. It is evident that Jack Brimble and George Scown had just as much right to practice; and with the assistance of popular prejudice, backed by the adoption of a certain " gravity" of manners to conceal their defective educations, might have been just as successful. I remain yours, $\mathrm{Sir}$,

\section{Binhamy Castle, Feb. 29, 1840.}

\section{POISONING WITH MURIATIC ACID.}

\section{To the Editor of THE LANCET.}

SIR :-If the following report of a case of suspected poisoning, by muriatic acid, be deemed worthy of a place in your valuable Periodical, it will be entirely at your service. I believe that no case of the kind has hitherto been reported in this country. I am, Sir, your most obedient servant,

Thomas Frederic Craw ford, Surgeon. Newcastle-on-Tyne, Feb. 21, 1840.

A woman, by name Smith, aged 40, who was reported, in the "Port-of-Tyne Pilot," to have died last autumn, from the effects of swallowing corrosive sublimate, took, with intent of poisoning herself, two ounces of a mixture used by her husband for the parpose of "browning gun-barrels." The following is a copy of the recipe:-

To tincture of steel and muriatic assed, equal quantities, add a few drops of corrosiv suplement.

Soon after she took the mixture, she vomited. In less than half an hour she was seen by a druggist, but did not vomit then, nor again. She answered questions rationally, and was sensible until she died, but made no complaint of heat, or pain, in the mouth, throat, or epigastrium. She had no thirst; no pulse could be felt at the extremities, and the heart's action was very feeble. The muscles of the extremities felt hard, as if contracted; she died in about five hours and a half after having taken the mixture. Two hours and a half before death she had two stools. A practitioner was called in, and she was treated, as is seen, without effect.

Autopsy, Fifteen Hours Post-moriem.

The body presented a thick layer of subcutaneous fat.

Chest.-The blood in the heart was fluid and black.

Abdomen.-Stomach contracted, and exhibited its mucous membrane thrown into ridges and furrows; the ridges were of a brown colour, as if charred, and when the surface was scraped with the nails, it could be readily peeled off, and the part exposed showed numerous small black granules. These granules seemed (at least, resembled) the colouring matter of blood changed by the action of some acid. The furrows were of a fine scarlet colour. No perforation of the stomach could be observed, but blood was found effused between the two layers of peritoneum, proceeding from its great curvatare. Appearances similar to these were noticed in the duodenum and jejunum. The middle of the pleura was examined, and found to be healthy. The lower part of the cesophagus was charred, and the epithelium could be readily peeled off; no other part of the intestinal canal was examined.

A friend and good chemist, Mr. Thomas Richardson, of this town, kindly examined a small portion of the poisonous mixture. The following is the result:-

"The reagents give a large quantity of free muriatic acid; also, free sulphuric acid, but in very small quantity, and combined with much iron, which seems to have 